\title{
Regulation of Intestinal Stem Cell Stemness by the Aryl Hydrocarbon Receptor and Its Ligands
}

\author{
Paul J. Wisniewski, Mitzi Nagarkatti and Prakash S. Nagarkatti* \\ Pathology, Microbiology and Immunology, School of Medicine, University of South Carolina, Columbia, SC, United States
}

Maintenance of intestinal homeostasis requires the integration of immunological and molecular processes together with environmental, diet, metabolic and microbial cues. Key to this homeostasis is the proper functioning of epithelial cells originating from intestinal stem cells (ISCs). While local factors and numerous molecular pathways govern the ISC niche, the conduit through which these processes work in concordance is the aryl hydrocarbon receptor (AhR), a ligand-activated transcription factor, whose role in immunoregulation is critical at barrier surfaces. In this review, we discuss how AhR signaling is emerging as one of the critical regulators of molecular pathways involved in epithelial cell renewal. In addition, we examine the putative contribution of specific AhR ligands to ISC stemness and epithelial cell fate.

OPEN ACCESS

Edited by:

Stefan Jordan

Charité - Universitätsmedizin

Berlin, Germany

Reviewed by:

Nan Gao,

The State University of New Jersey,

United States

Harry D. Dawson,

Agricultural Research Service (USDA),

United States

*Correspondence:

Prakash S. Nagarkatti prakash@mailbox.sc.edu

Specialty section:

This article was submitted to

Mucosal Immunity,

a section of the journal

Frontiers in Immunology

Received: 07 December 2020 Accepted: 08 February 2021 Published: 10 March 2021

Citation:

Wisniewski PJ, Nagarkatti M and Nagarkatti PS (2021) Regulation of Intestinal Stem Cell Stemness by the

Aryl Hydrocarbon Receptor and Its Ligands. Front. Immunol. 12:638725.

doi: 10.3389/fimmu.2021.638725
Keywords: gut epithelium, intestinal stem cells, aryl hydrocarbon receptor, aryl hydrocarbon receptor ligands, morphogenetic pathways

\section{INTRODUCTION}

Maintenance of intestinal homeostasis is governed extensively by the integration of both molecular and immunological processes. This integration is further mediated by the presence of enteric microorganisms that colonize the gastrointestinal (GI) tract. The crosstalk between intestinal microorganisms and the host in which they reside occurs at the gut mucosa, a specialized intestinal tissue that represents one of the body's most important interfaces with the environment. The gut mucosa is comprised of the gut epithelium, a monolayer of epithelial cells that has critical functions in avoiding self-digestion, contending with luminal contents without eliciting overt immune responses and promoting self-tolerance (1). Due to its significance, the gut epithelium demonstrates an astounding renewal capacity as the entire intestinal lining is replenished completely within 5 days (2-4). Homeostasis of the gut epithelium itself is maintained by an intestinal stem cell (ISC) compartment that resides at the base of intestinal crypts, giving rise to specialized epithelial cell lineages (5). As such, these ISCs are crucial for the renewal of the differentiated progeny that comprise the gut epithelium. However, this rapid rate of renewal imposes greater demands on the cellular hierarchy of the gut epithelium as well as a greater risk of developing intestinal malignancies (6). What remains to be explored is the extent to which ISCs can be influenced by environmental factors to maintain or restore intestinal homeostasis.

Of note is the modulation of immune responses from compounds derived from both endogenous and exogenous sources via the aryl hydrocarbon receptor (AhR), a ligand-activated transcription factor that integrates environmental, dietary, microbial and metabolic cues to control transcriptional programs in a ligand-, cell- and context-specific manner (7). While there are some recent reviews on the role of $\mathrm{AhR}$ in the regulation of inflammation through induction of antiinflammatory signaling involving IL-10, IL-22, prostaglandin $\mathrm{E}_{2}$, and Foxp3 (8), to the best of our knowledge, there are no reviews on the role of AhR in ISC function and regulation. Using 
floxed Ahr to Villin-Cre mice, Metidji and colleagues have recently shown AhR expression in intestinal epithelial cells (IECs) to be critical for ISC homeostasis and gut barrier integrity as it plays a dominant role in tempering Wnt signals (9). Expression of tryptophan metabolizing enzyme, indoleamine 2,3-dioxygenase 1 (IDO1), in IECs has also shown to enhance differentiation of secretory cells and mucus production in IEC-specific transgenic mice (mouse line pVilEGFP/IDO1) challenged with dextran sodium sulfate (DSS), 2,4,6-trinitrobenzene sulfonic acid (TNBS) or enteropathogenic Escherichia coli (10). Because induction of IDO depends on AhR expression and kynurenine produced by IDO acts as an AhR agonist, these studies suggested that AhR promotes intestinal homeostasis. Additionally, AhR has shown to sense genotoxic compounds found in the diet and protect stem cells against genotoxic stress through the induction of IL-22 by innate lymphocytes (11). Together, these are a few examples that highlight the extent to which AhR activation mediates the regulation ISC stemness. In this review, we examine current knowledge on how AhR activation can modulate ISC stemness through essential signals of epithelial cell differentiation.

\section{THE INTESTINAL STEM CELL COMPARTMENT}

While several populations of ISCs have been described, the driving force of epithelial cell renewal and tissue repair are the fast-cycling crypt base columnar (CBC) stem cells marked by a leucine-rich-repeat containing G-protein coupled receptor 5 (LGR5) (2, 12, 13). These ISCs, or LGR5-positive (+) CBC stem cells, divide daily and reside at the crypt base (14) (Figure 1A). Due to the limited space of intestinal crypts, ISCs undergo 'neutral competition' in which half are pushed out of the ISC niche at random to the above transit-amplifying (TA) compartment where they then become committed progenitor cells $(14,15)$. Immediately preceding TA cells is a slow dividing 'reserve stem cell' or position $4 /+4$ cell population, counting the adjacent cells from the crypt base, that replenishes the pool of active stem cells under normal circumstances or fully differentiates into epithelial cells in the advent of a disrupted LGR5 + compartment such as during acute inflammation (16, 17). What governs this variable stem cell activity and states of competency are niche-derived signals, such as growth factors and wingless-related integration site (Wnt) ligands, from neighboring Paneth cells within the gut epithelium and from subepithelial mesenchymal cells, including the rare winged helix transcription factor Foxl1 expressing (Foxl1+) telocytes which maintain intestinal crypt cell proliferation and promote homeostatic renewal of the gut epithelium, as well as the recently identified $\mathrm{CD} 34+\mathrm{Gp} 38+$ mesenchymal cells which rapidly respond to intestinal injury and produce a myriad of factors involved in ISC maintenance and tissue repair (18-21). ISCs are therefore subjected to and directed in activity by a host of proximal signals that encompass the ISC niche. What orchestrates the generation of new epithelial cells from ISCs and their subsequent functional specialization in tandem with ISC niche-derived signals are several molecular pathways. Among these are the Wnt/ $\beta$-catenin,
Notch, Hedgehog and bone morphogenic protein (BMP), as well as the epidermal growth factor receptor (EGFR) and ephrin (Eph) pathways which direct ISC proliferation and cell positioning (21). Here, we provide an overview of select signals relevant to AhR activation (Figure 1B).

\section{AHR SIGNALING AND REGULATION}

The AhR is a basic helix-loop-helix (bHLH) ligand-dependent transcription factor that responds to a variety of ligands due to its malleable ligand-binding site and is the only member of the bHLH superfamily of transcription factors that can be activated by ligands (22). Signaling of the AhR involves a central PERARNT-SIM (PAS) domain that is involved in DNA recognition, ligand binding, and chaperone interactions which are critical for ensuing transcriptional events (Figure 2). In its inactivated form, the AhR resides in the cytoplasm within a chaperone complex comprised of heat-shock protein 90 (Hsp90), p23, $\mathrm{X}$-associated protein 2 (XAP2), and AhR-associated protein 9 (ARA9) (23). Hsp90 preserves a conformational state of the AhR that prevents unsolicited translocation into the nucleus and allows binding of a ligand, while the phosphoprotein p23 facilitates the interaction between the AhR and Hsp90 $(24,25)$. XAP2 regulates AhR turnover and ARA9 augments AhR signaling by increasing available binding sites and by increasing the amount of cytosolic $\operatorname{AhR}(26,27)$. Upon binding of a ligand, the AhR undergoes structural modifications that expose nuclear localization sequences in which two adjacent protein kinase C sites become phosphorylated (28-30). Once translocated, AhR dissociates from its chaperone complex as AhR receptor nuclear translocator (ARNT) replaces Hsp90 forming a heterodimer (23). This AhR-ARNT heterodimer binds to cis elements of DNA that contain aryl hydrocarbon responsive elements (AhREs, also known as xenobiotic- or dioxin-response elements). These regulatory elements containing the core sequence 5'-TNGCGTG-3' can be found in the promoter regions of numerous target genes including cytochrome P450 enzymes such as CYP1A1, which metabolizes AhR ligands, thereby suppressing its activation (31). Once bound to AhREs, this complex acts as a transcriptional complex that can alter transcriptional activity and chromatin structure through histone acetyltransferase and methyltransferase activity (32). AhR activity is tightly controlled by two primary mechanisms in which the first involves proteolytic degradation $4 \mathrm{~h}$ after the ligand-bound AhR has associated with AhREs and is then exported from the nucleus (33). The second involves the AhR repressor protein (AhRR) which is structurally analogous to the AhR but does not require a ligand to translocate into the nucleus and interacts with ARNT. It is upregulated upon AhR activation and therefore acts as a transcriptional repressor (34).

\section{INTERACTION BETWEEN THE AHR AND SELECT MOLECULAR SIGNALS OF ISC HOMEOSTASIS}

At present, an increasing volume of evidence indicates that the AhR is a pleiotropic regulator of molecular processes that 
A
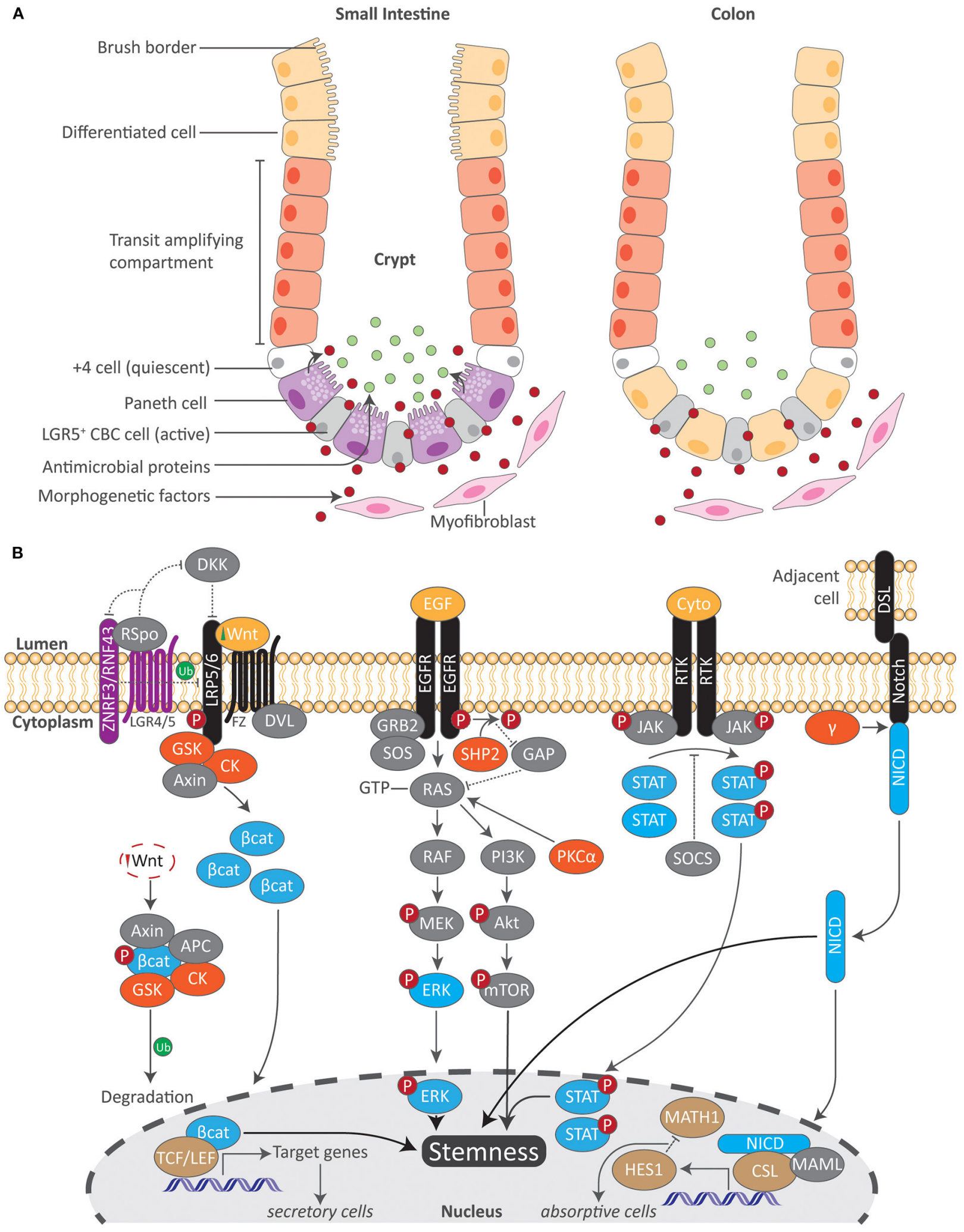

FIGURE 1 | Overview of the intestinal stem cell compartment and molecular cascades related to AhR signaling. (A) Active and quiescent stem cells reside at the crypt base in both the small and large intestine. Local morphogenetic factors produced from small intestinal Paneth and subepithelial mesenchymal cells regulate ISC

(Continued) 
FIGURE 1 | activity. As stimulated ISCs migrate upward into the transit amplifying compartment, they then become committed differentiated cells. A brush border resides at the apical surface of epithelial cells in the small intestine which maximizes the absorptive surface area. In contrast, both Paneth cells and a brush border are absent in the colon. While the absence of Paneth cells in the colon results in decreased antimicrobial proteins, the colon employs other mechanisms to maintain intestinal homeostasis. LGR5 leucine-rich-repeat containing G-protein coupled receptor 5, CBC crypt base columnar. (B) Numerous molecular pathways orchestrate epithelial cell fate in concordance with local morphogenetic factors within the ISC. Key proteins in each signaling pathway (blue) interact with transcription factors (brown) to regulate gene transcription. Upstream of this, additional kinases (orange) modulate these pathways. Both Wnt/ $\beta$-catenin and Notch signaling play a pivotal role in regulating the differentiation of either secretory or absorptive epithelial cell types. Together with EGF/MAPK and JAK/STAT signaling as well as others, these pathways work in tandem to regulate ISC stemness. Akt protein kinase B, APC adenomatous polyposis coli, Bcat beta catenin, CK casein kinase, CSL CBF1/SU/LAG1, Cyto cytokine, DKK Dickkopf, DSL Delta/Serrate/LAG2 transmembrane ligands, DVL Disheveled, EGF epidermal growth factor, EGFR epidermal growth factor receptor, $\gamma$ gamma secretase, GAP GTPase-activated protein, GRB2 growth factor receptor-bound protein 2, GSK glycogen synthase kinase, HES1 hairy and enhancer of split 1, JAK/STAT janus kinase/signal transducer and activator of transcription, MAML Mastermind-like, MATH1 Protein atonal homolog 1 , mTOR mammalian target of rapamycin, NICD Notch intracellular domain, PI3k phosphoinositide 3-kinase, PKCalpha protein kinase c alpha, RNF43 ring finger 43, Rspo respondins, RTK receptor tyrosine kinase, SHP2 Src homology 2 phosphatase 2, SOCS suppressors of cytokine signaling, SOS son of sevenless, TCF/LEF T-cell factor/lymphoid enhancer-binding factor, Ub ubiquination, ZNRF3 zinc and ring finger 3.

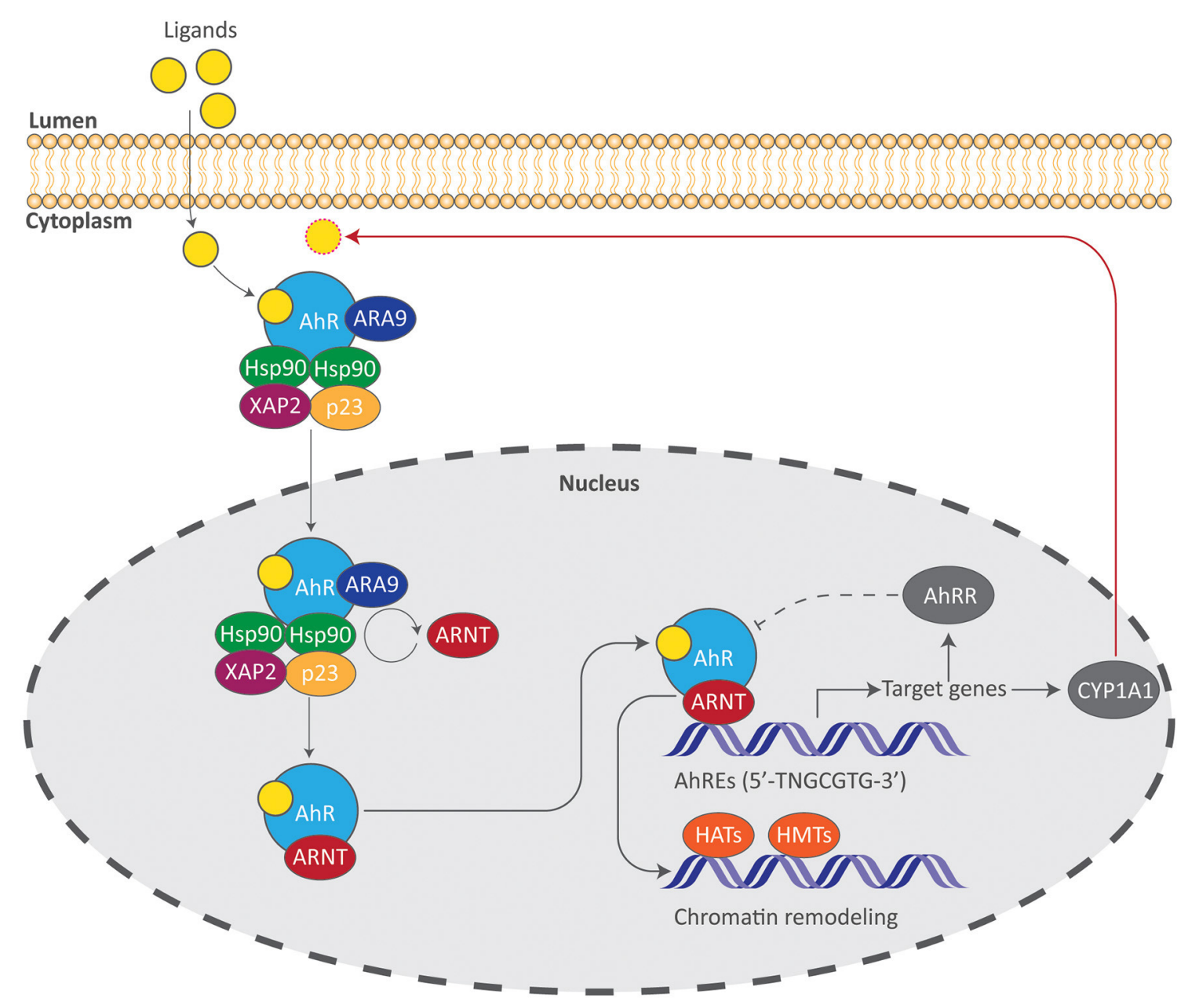

FIGURE 2 | The AhR signaling pathway. Induction of AhR signaling requires binding of a ligand, allowing the AhR complex to translocate into the nucleus and initiate transcriptional events. Gene products such as the AhR repressor protein (AhRR) and the cytochrome P450 enzyme CYP1A1 suppress AhR signaling by acting as a direct antagonist to the AhR (dotted line) or by metabolizing AhR ligands (red arrow). AhREs aryl hydrocarbon responsive elements, ARA9 AhR-associated protein 9 , ARNT AhR receptor nuclear translocator, HATs histone acetyltransferases, HMTs histone methyltransferases, Hsp90 heat-shock protein 90, XAP2 X-associated protein 2.

extend beyond its historical role as a xenobiotic sensor. In particular is its emerging role in immune development and function at barrier surfaces including the skin, respiratory tract and GI tract (35). In addition, AhR activation may contribute to intestinal homeostasis by regulating ISC stemness and progeny through morphogenetic signals and others as summarized here 


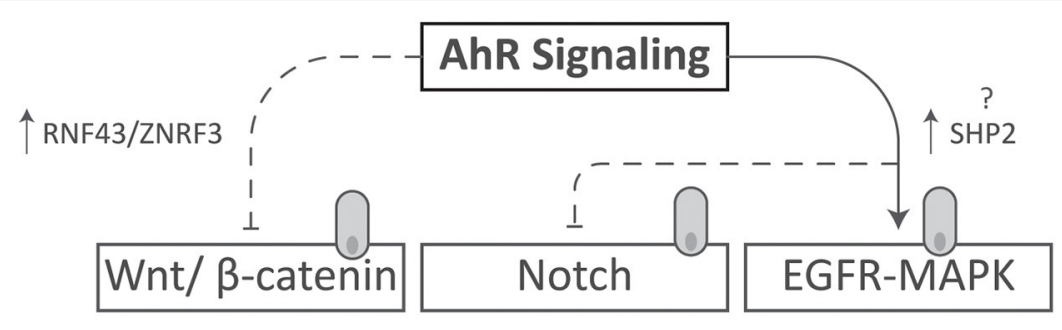

\section{AhR Ligands}
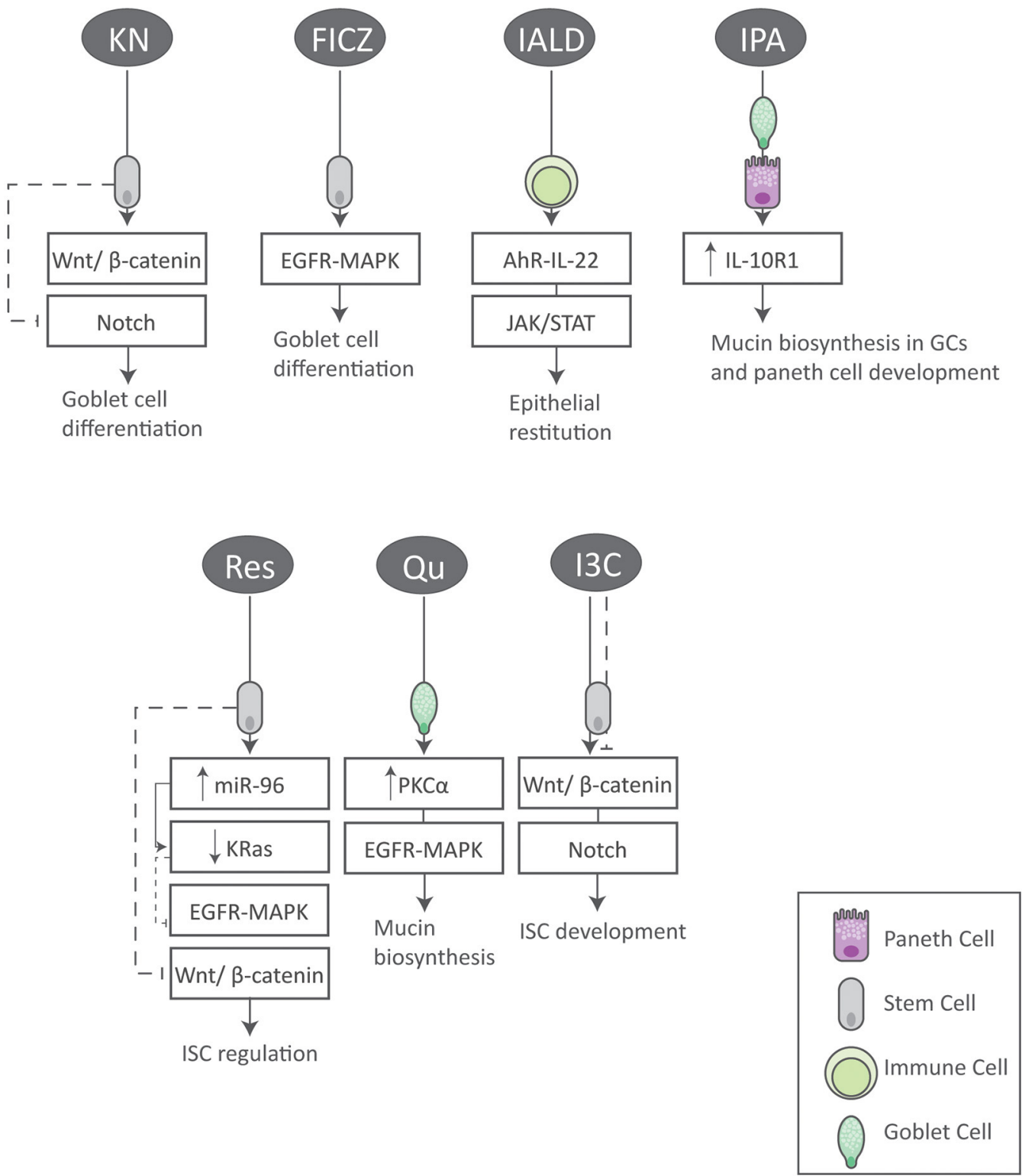

FIGURE 3 | Summary of AhR signaling and its ligands on aspects of ISC homeostasis. Activation of the AhR regulates the Wnt, Notch and EGFR/MAPK signaling pathways in ISCs. In addition, specific AhR ligands synergize with key stemness pathways within various cell types to exert unique and beneficial effects. FICZ tryptophan derivative 6-formylindolo (3, 2-b) carbazole, I3C indole-3-carbinol, IALD indole-3-aldehyde, IL-10R1 interleukin-10 receptor 1, IPA indole-3-propionic acid, GC goblet cell, KN kynurenine, Qu quercetin, Res resveratrol. 
(Figure 3). As so eloquently defined by Aponte and Caicedo, stemness in this regard combines the ability of ISCs to perpetuate its lineage, to give rise to differentiated epithelial cells, and to interact with its environment to maintain a balance between quiescence, proliferation and regeneration (36).

\section{Wnt/ $\beta$-catenin}

The canonical $\mathrm{Wnt} / \beta$-catenin pathway plays a pivotal role in the establishment of tissue architecture during development and in homeostasis of adult tissues (37). In the intestine, it is critical for the proliferation and maintenance of ISCs as well as for the differentiation of goblet cells (GCs) $(38,39)$. Here, $\beta$-catenin is an essential cytoplasmic signal transducer (40). Given its role in the maintenance of intestinal homeostasis, aberrant $\mathrm{Wnt} / \beta$-catenin signaling has shown to be a hallmark of colorectal cancer (CRC) development characterized by a loss of the tumor suppressor adenomatous polyposis coli (APC) and hyperactivation of $\mathrm{Wnt} / \beta$-catenin signals (41). In contrast, a putative mechanism by which $A h R$ activation regulates the $W n t / \beta$-catenin pathway has recently been determined to be through the activity of E3 ubiquitin ligases RNF43 and ZNRF3 which target Wnt frizzled receptors for degradation in ISCs, thereby inhibiting Wnt signaling (42). Specifically, selective ablation of the AhR or overexpression of CYP1A1 in IECs potentiated ISC proliferation (as indicated by Ki67 expression) and inflammation-induced tumorigenesis (9). This was accompanied by a reduced RNF43 and ZNRF3 expression, and a concomitant increase in $\beta$-catenin and Wnt target gene expression (9). These results show that AhR deficiency or the degradation of its ligands in IECs promotes the hyperactivation of Wnt signaling due to a selective defect in the induction of key negative pathway regulators. In turn, this highlights the potential of physiological AhR signals to temper Wnt responsiveness in ISCs. Using an in vitro model of wound healing, Kasai et al. have further shown that disruption of adherens junctions by Spinner Modification (S-MEM) in Caco2 cells enhances the interaction between $\beta$-catenin and AhR but not with TCDD treatment (an AhR agonist) as evidenced by immunoprecipitation and that the ablation of $\beta$-catenin by siRNAs enhances the induction of CYP1A1 mRNA with S-MEM or TCDD treatment (43). This suggests that while ablation of AhR may potentiate Wnt signals, ablation of $\beta$-catenin may then potentiate AhR signals in response to tissue injury though direct degradation of $\beta$-catenin by ligand-activation of the AhR remains questionable. As recently demonstrated, only one primary association between $\beta$-catenin and the AhR in vitro could be found after failing to induce $\beta$-catenin degradation by AhR activation with various AhR ligands in multiple cell lines, that $\beta$-catenin does enhance AhR-mediated transcriptional activation (44). As such, the most significant discrepancy is whether the above interaction is assessed in vivo or in vitro. Consequently and as the findings of Kasai et al. suggest, that despite TCDD not enhancing the interaction between $\beta$-catenin and the AhR, local factors following tissue injury may act as endogenous AhR ligands to then temper Wnt signals which could explain the hyperactivation of Wnt signals in vivo following IEC-specific ablation of AhR.

\section{EGFR-MAPK/ERK and Notch}

Epidermal growth factor (EGF) is an extracellular ligand produced from neighboring Paneth and subepithelial mesenchymal cells that plays a pivotal role in intestinal growth as it potentiates cell survival and ISC proliferation through downstream Mitogen-activated protein kinase (MAPK) signals (45-47). MAPKs are vital signaling molecules that influence a broad range of cellular processes including proliferation and differentiation in IECs (47). Together with the Wnt/ $\beta$-catenin pathway, MAPK signaling governs ISC stemness as well as their differentiation into TA cells (48). Of the many MAPK signaling pathways, the Ras/Raf/MEK/ERK system is the best characterized which culminates in the terminal phosphorylation, and thus activation, of the MAPKs ERK1 and ERK2 (Figure 2B). MAPK/ERK signaling is potentiated by the Src homology 2 (SH2) phosphatase 2 (SHP2), a ubiquitously expressed cytoplasmic phosphotyrosine ( $\mathrm{pY}$ ) phosphatase whose target substrate is the EGF receptor (EGFR) which is a transmembrane receptor tyrosine kinase (RTK) (49). Deletion of SHP2 in IECs results in a decreased ERK phosphorylation (50) whereas its activation confers resistance to dextran sulfate sodium (DSS)-induced colitis and Citrobactoer rodentium (C. rodentium) infection through the MAPK/ERK pathway (51). At present, the extent to which AhR activation works in tandem with SHP2-MAPK/ERK signaling to promote intestinal homeostasis remains largely unknown; however, its role in potentiating MAPK/ERK signals must be highlighted. Independent of SHP2, AhR activation by the tryptophan derivative 6-formylindolo (3, 2-b) carbazole (FICZ) has indeed shown to ameliorate DSS-induced colitis and exclusively promote the MAPK/ERK-dependent differentiation of GCs (52). Importantly, this selectivity for GCs occurs in parallel with a suppression of Notch signals as indicated by a down-regulation of the Notch intracellular domain (NICD) which is released upon Notch activation (Figure 1B). Like the $\mathrm{Wnt} / \beta$-catenin pathway, Notch signaling has a profound effect on intestinal development as it regulates ISC stemness and epithelial cell fate $(53,54)$. In this regard, Notch signaling suppresses the differentiation of GCs and its actions may therefore be countered by the activation ERK as previously described (51). Taken together, these findings suggest that AhR-MAPK/ERK signaling promotes intestinal homeostasis by selecting for the differentiation of GCs.

\section{THE CONTRIBUTION OF AHR LIGANDS TO ISC HOMEOSTASIS}

\section{Tryptophan Metabolites}

Tryptophan is an essential amino acid and is a precursor for several bioactive molecules, especially serotonin; however, only a small percentage of tryptophan is metabolized into serotonin. Instead, 95\% of tryptophan is metabolized into kynurenine $(\mathrm{KN})$ which plays a critical role in cellular energy production following its eventual conversion into nicotinamide adenine dinucleotide $(\mathrm{NAD}+)$ through the kynurenine pathway (KP) $(55,56)$. What remains of the $\mathrm{KN}$ pool under physiological conditions is converted into kynurenic acid (KA) (56) and 
both metabolites are potent AhR ligands $(57,58)$. Interestingly, $\mathrm{KN}$ may regulate epithelial cell fate through the AhR. Of note are recent findings demonstrating that both tryptophan and KN promote GC differentiation in HT-29 cells as determined by Muc2 gene expression (59). Analyses confirmed that both inhibition of KN synthesis by 1-Methlytryptophan (1-MT) and inhibition of AhR signaling by its antagonist $\alpha$-naphthoflavone suppresses Muc2 gene expression, suggesting a loose connection between AhR activation and $\mathrm{KN}$ synthesis in the production of GCs. Importantly however, while $\mathrm{KN}$ was shown to increase the protein expression of $\beta$-catenin relative to NICD (Wnt vs. Notch signals), these effects were dependent on the media in which the cells were grown (i.e., DMEM vs. RPMI) which can vary in amino acid and glucose content (59). Interestingly, an early report by Park et al. has indicated that AhR is highly expressed in LGR5+ stem cells in the small intestine and that administration of its potent ligand FICZ, a tryptophan derivative generated by ultraviolet $\mathrm{B}$ irradiation (60), inhibits the development of intestinal organoids in a concentration-dependent manner in vitro as indicated by significant reduction in absolute numbers of organoids and slightly reduces Paneth cells in the small intestine with a concomitant reduction in crypt length and a reduction in colonic crypt length in vivo (61). It was also found that FICZ reduced the protein expression of active $\beta$-catenin in organoids derived from small intestinal crypts (perhaps due to a loss of morphogenetic factors produced from crypt Paneth cells) though increased the gene expression of the transcription factor $A T O H 1$, which promotes the differentiation of secretory lineages from ISCs, as well as altered the gene expression of other morphogenetic pathway markers (61). Though no changes in GC number were observed following FICZ administration, the observed increase of ATOH1 expression highlights the putative role of FICZ in promoting the differentiation of GCs as previously shown (52). In all, these findings suggest that KN promotes the differentiation of GCs in tandem with AhR activation but that these actions may be dependent on additional local factors such as other amino acids. In addition, FICZ modulates multiple morphogenetic pathways and its effect on epithelial cell fate may be consistent with $\mathrm{KN}$ in promoting the differentiation of GCs but the suppression of Paneth cells and thus the extent to which FICZ modulates differentiation of secretory lineages warrants further investigation. Further, the selective reduction in Paneth cell number may reflect regionspecific effects of FICZ on epithelial cell fate.

\section{Microbiota-Derived}

The gut microbiota encompasses a diverse array of microbial taxa that colonize the full length of the GI tract, consisting of approximately $3.8 \times 10^{13}$ cells in total (62). The majority of the gut microbiota is harbored in the colon and modulates its host's physiology by the production of microbiota-derived metabolites that act upon multiple organ systems through various "hostmicrobe metabolic axes" (63). These metabolites include (but are not limited to) tryptophan catabolites and short-chain fatty acids (SCFAs) originating from the bacterial fermentation of dietary protein and soluble fiber $(64,65)$. These metabolites serve as AhR ligands of varying affinities and may affect ISC stemness.

\section{Tryptophan Catabolites}

As mentioned above, much of dietary tryptophan is metabolized into $\mathrm{KN}$ through the $\mathrm{KP}$ as the majority of ingested protein is digested and absorbed in the small intestine (66). Depending on total intake however, excess protein and amino acids (6$18 \mathrm{~g}$ /day) may reach the colon and become accessible to the resident gut microbiota (67). While there are bacteria that specialize in the proteolytic fermentation of dietary protein, the degradation of tryptophan appears to be a ubiquitous function shared among several bacterial species that reside throughout the GI tract $(65,68)$. Most notably is the ability of the gut microbiota to convert tryptophan into indole and indole derivatives via the enzyme tryptophanase (TnaA) $(69,70)$. To date, research indicates that a variety of both Gram-positive and -negative bacteria are capable of producing large amounts of indole and consequently, that indole acts as a significant signaling molecule within microbial communities having been implicated in the control of diverse aspects of bacterial physiology as reviewed elsewhere (71). Given its importance in shaping the ecological landscape and physiology of the gut microbiota, bacteria-derived indole and its derivatives have a significant impact on host gut physiology and health. While several derivatives of indole exist, here we focus on the AhR ligands indole-3-aldehyde (IALD) and indole-3-propionic acid (IPA) and their prospective contribution to ISC stemness as these two ligands have shown to directly impact ISC stemness to date.

Among the many aspects of immune development that AhR signaling plays a role in, notably is its impact on innate lymphoid cells (ILCs). ILCs are a heterogenous population of immune cells that are non- $\mathrm{T}$ and non-B lymphocytes which lack antigen-specific receptors and are hence activated through cytokine signaling (72). ILCs have distinct groups that express transcription factors and produce signature cytokines including group 3 ILCs (ILC3s), which release interleukin (IL)-22 upon AhR activation (73). This AhR-IL-22 axis expressed in ILC3s is critical for the maintenance of intestinal homeostasis as AhR deficiency in $\mathrm{ROR} \mathrm{t}^{+}$ILCs increases susceptibility to C. rodentium infection due to a lack of IL-22 production (74). Likewise, AhR deficiency in mice causes an increase in Th17 cells and an expansion of commensal segmented filamentous bacteria (SFB) due to a concomitant reduction in IL-22 (75). Further, haplodeficiency of ROR $\gamma$ t with genetic ablation of AhR spontaneously induces colitis indicating the importance of ROR $\gamma \mathrm{t}$ in maintaining the ILC3 compartment and subsequent IL-22 production in tandem with AhR activation (75). Additional findings confirm that treatment with IL-22 increases ISC stemness both in vivo and ex vivo as well as reduces intestinal pathologies associated with graft-versus-host disease (76). In this same study, it was also found that STAT3 activation was crucial for both organoid formation and IL-22 mediated epithelial regeneration highlighting the importance of JAK/STAT signaling in ISC stemness. While evidence also illustrates a Notch-AhR-IL-22 axis which regulates colon tissue homeostasis through the development of IL-22 producing ILCs (77-79), an earlier report has shown that IALD produced primarily from Lactobacillus reuteri (L. reuteri) increases the production of IL-22 in indoleamine 2,3-dioxygensase 1 (IDO1) deficient mice, 
conferring antifungal resistance and mucosal protection when challenged with Candida albicans (C. albicans) or DSS (80). As expected, these beneficial effects were not observed in AhRdeficient mice emphasizing the AhR-dependent release of IL-22 (80). In addition, a more recent study explored the protective effect of $L$. reuteri on the integrity of the gut mucosa in an attempt to elucidate the therapeutic benefits of Lactobacilli often found in yogurt (81). The authors reported that $L$. reuteri upregulated IL-22 production and stimulated ISC regeneration (as indicated by an increase in LGR5+ stained cells) in both organoid/LPL co-cultures and in mice which was also observed with IALD administration. Lastly and similar to the findings of Lindemans et al. (76), the secretion of IL-22 by LPLs stimulated with L. reuteri or IALD increased the phosphorylation of STAT3 both in vivo and ex vivo. Together, these findings suggest that IALD derived from Lactobacilli plays a pivotal role in the production of IL-22 within AhR-expressing immune cells and that through the AhR-IL-22 axis, promotes ISC regeneration and epithelial restitution which is dependent on STAT3 activation.

IL-10 is a potent anti-inflammatory cytokine whose significance is well established in IBD. This important cytokine signals through the IL-10 receptor ligand-binding subunit (IL-10R1) and is induced during inflammation to suppress the production of proinflammatory mediators in IECs (82). To date, studies indicate that IL-10 regulates mucin biosynthesis in GCs and that IL-10 is critical for Paneth cell development and function $(83,84)$. While the direct effect of IL-10 on IEC function and development is less explored, these findings suggest that IL-10 may have an influence on secretory epithelial cells. Nevertheless, a recent report has shown that both IALD and IPA induce IL-10R1 expression in vitro and that this induction requires AhR signaling as the ablation of its dimeric partner ARNT prevented the indole-dependent induction of IL-10R1 (85). Moreover, only wild-type Escherichia coli (E. coli) were able to generate IALD and IPA, and thus induce epithelial IL-10R1. Collectively, these results indicate a putative role of IL-10 signaling in secretory epithelial cell function and development, and that the microbiota-derived indole derivates IPA and IALD augment the therapeutic effects of IL-10 via AhR signals in the preservation of mucosal homeostasis.

\section{Short-Chain Fatty Acids}

SCFAs are one of the major end products of microbial fermentation and are formed from carbohydrate, protein and glycoprotein precursors by anaerobic bacteria (86). Principal SCFAs are acetate, propionate and butyrate in which all are important sources of carbon and energy for host tissues (87). These organic acids are absorbed through the gut mucosa and can modulate host energy homeostasis through interactions between chemosensory enteroendocrine cells $(87,88)$. Interestingly, butyrate is a critical energy source for colonocytes (89) and exhibits therapeutic effects like that of other AhR agonists including induction of Treg cells, anti-inflammatory responses as well as the induction of IL-22 (90-93). While recent data show that all three SCFAs enhance AhR responsiveness in vitro primarily as histone deacetylase (HDAC) inhibitors (94), additional findings demonstrate that butyrate can activate
AhR signaling independent of its role as an HADC inhibitor suggesting that it is a direct AhR ligand as well (95). As recently reviewed (96), studies that have investigated the effect of butyrate on ISCs are discrepant, however. For instance, as butyrate is a primary energy source for colonocytes (89), it can facilitate ISC proliferation through gluconeogenesis (97) and improved microcirculation by dilating colonic resistance arteries (98). In contrast, butyrate has shown to suppress colonic stem cell proliferation by HDAC inhibition and Foxo3 regulation, a transcription factor that governs cell proliferation and longevity (99). While disagreements remain, studies to date overall posit that butyrate regulates ISC proliferation in the colon and controls the differentiation of GCs. Still however, the extent to which butyrate regulates ISC stemness via AhR activation remains elusive.

\section{Plant-Derived}

Given the ubiquitous influence of AhR signaling in the maintenance of barrier surfaces and its ability to ligate numerous ligands, the efficacy of natural AhR ligands in the treatment of inflammatory disorders in murine models has been extensively explored. Of note are the phytochemicals quercetin, resveratrol and indole-3-carbinole (I3C). At present, there are no studies that have examined the effects of these flavonoids in IBD patients but the therapeutic aspects thereof have been extensively studied due to their potent antioxidant and anti-inflammatory properties (100). While each indeed has potent therapeutic effects in the treatment of experimental IBD (101), recent evidence suggests that these effects extend beyond modulation of immune responses and inflammation in which maintenance of ISC stemness may also be a benefit.

Quercetin is an abundant polyphenol found in many natural foods including fruits, vegetables, and nuts (102). Like quercetin, resveratrol is a polyphenol best known to be enriched in the skins and seeds of red grapes used to make red wine (103). Due to their low affinity, both are corroborated to be indirect AhR ligands and control AhR responsiveness by inhibiting the actions of CYP1A1 which prevents the metabolic turnover of the potent AhR agonist FICZ (104). As shown above, multiple signaling pathways, including MAPKs and canonical $\mathrm{Wnt} / \beta$-catenin cascades, regulate cellular turnover of the intestinal epithelium. Expectedly, oncogenic mutations inducing the hyperactivation of both pathways perturb intestinal homeostasis and result in intestinal malignancies. Of note are the oncogenic mutations of K-Ras (KRAS) within the EGFR-MAPK/ERK pathway which has shown to be involved in CRC development $(105,106)$. Resveratrol has been found to possess a broad-spectrum of health benefits including anti-cancer activities (107) and findings by Saud et al. specify that resveratrol acts directly to suppress KRAS expression (108). Using a conditional knockout model of APC in mice supplemented with resveratrol, the authors determined that resveratrol inhibits tumor growth and proliferation which is accompanied by a reduction in LGR5, KRAS and nuclear $\beta$-catenin expression. Interestingly, mRNA levels of KRAS did not change with resveratrol but instead, an $80 \%$ increase in the expression of the miRNA miR-96 was observed. As miR96 has shown to regulate the translation of KRAS mRNA (109, 
110), the authors concluded that the mechanism through which resveratrol confers its therapeutic effects is the post-translational modification of KRAS by miRNAs. Similarly, recent findings of Damiano and colleagues suggest that the therapeutic effects of quercetin are also enacted via the MAPK/ERK pathway particularly as it relates to GC function (111). In human intestinal GC-like LS174T and Caco-2 cells, the authors observed a significant increase in MUC2 and MUC5AC expression in both cell lines following exposure to quercetin and that these effects were dependent on the induction of both MAPK/ERK and protein kinase $\mathrm{C}$ alpha $(\mathrm{PKC} \alpha)$ signals. $\mathrm{PKC}$ is a family of lipidsensitive serine/threonine protein kinases that regulate various cellular functions including cell proliferation, differentiation, migration, adhesion and apoptosis (112). Importantly, PKC $\alpha$ activity is a strong agonist of ERK signaling via Ras activation and works in parallel to regulate cell cycle withdrawal in IECs (113). Taken together, these studies suggest that resveratrol and quercetin promote intestinal homeostasis through opposing directions of the same signaling cascade; resveratrol regulates cell proliferation by inhibiting Wnt and MAPK/ERK signals (via the suppression of KRAS) whereas quercetin modulates the biosynthesis of mucins in intestinal GCs via the activation of MAPK/ERK and PKC $\alpha$ signals. Regarding AhR signaling, quercetin may confer its effects on intestinal GCs indirectly by allowing the FICZ-AhR-MAPK/ERK axis discussed above to ensue whereas resveratrol may exert its therapeutic effects via the induction of miR-96 which has shown to be regulated by the AhR in the lung (114).

I3C is a breakdown product of glucobrassicin, a sulfurcontaining compound that is rich in cruciferous vegetables such as broccoli and cabbage and is converted primarily into $3,3^{\prime}$ diindolylmethane (DIM) due to the acidic environment in the stomach upon digestion (115). I3C has shown much promise in the treatment of IBD as we have recently demonstrated that it prevents colitis via the induction of IL-22 (116), further highlighting the importance of the AhR-IL-22 axis in intestinal homeostasis. With regard to ISC stemness, a recent report by Park et al. further associates I3C-AhR induction with both Wnt and Notch signals in the regulation of GC differentiation (117). Similar to their earlier report using FICZ (61), administration of I3C by oral gavage inhibited the development of intestinal organoids in an AhR-dependent manner as indicated by a decrease in the proliferation of both ISCs and TA cells. RNA expression analyses of lineage specific genes in cultured organoids further concluded that I3C directly impacts the development of GCs, Paneth cells and enterocytes such that I3C increases MUC2 and lysozyme expression but decreases intestinal alkaline phosphatase (IAP) expression. In addition, and in contrast to their previous report, GCs were increased in I3Ctreated mice. Given the preferential increase of genes related to secretory epithelial cell types, additional analyses confirmed that $\mathrm{I} 3 \mathrm{C}$ indeed potentiates $\mathrm{Wnt}$ but suppresses Notch signals as evidenced by an increase in $\beta$-catenin and a decrease in Notch protein expression as well as in HES1 RNA expression, a transcription factor activated downstream of Notch signaling which suppresses ATOH1. While these findings suggest that I3C potentiates Wnt signaling, it may be context dependent as Metidji et al. have demonstrated that dietary I3C tempers Wnt hyperactivity in Villin ${ }^{C r e} R 26^{L S L-C y p 1 a 1}$ mice co-challenged with azoxymethane (AOM)/DSS by enhancing the expression of ZNRF3 and RNF43 (9). This discrepancy might be due to mode of administration of $\mathrm{I} 3 \mathrm{C}$ as purified diets may potentiate differential effects on intestinal health in comparison to normal chow (118). In sum, these findings posit that I3C plays a direct role in the development of ISCs via the AhR perhaps in a context-specific manner to maintain intestinal homeostasis and indicate that this regulation is likely mediated by both Wnt and Notch signals.

\section{CONCLUSIONS}

The ISC niche is complex and is the epicenter from which all intestinal epithelial cells arise. The fate of these stem cells and the function of their differentiated progeny are driven by varying local factors whose actions are coordinated through numerous signaling cascades that blend to govern ISC stemness. To add to this complexity, evidence reported herein highlights the extensive integration of AhR activation by various AhR ligands in the regulation of such pathways associated with ISC stemness. What proves challenging moving forward is addressing the promiscuous nature of AhR signaling itself. To remedy this, animal studies that investigate the effects of AhR deficiency in a cell-specific manner together with global ablation could provide more insight into the exact mechanisms through which the AhR exerts its effects. In addition, mode of dietary ligand administration (refined diets vs. intraperitoneal injection vs. oral gavage) should be strongly considered as each method could differentially affect experimental outcomes. Altogether, while much of the responses from AhR activation are context- and cell-dependent, the present findings illustrate the ubiquitous effects of $\mathrm{AhR}$ signaling in the maintenance of the ISC niche. What remains to be explored further is the extent to which both the mucosal immune system and the induction of molecular cascades in epithelial cells work in tandem with the AhR to regulate ISC stemness and epithelial cell fate.

\section{AUTHOR CONTRIBUTIONS}

PW: wrote the manuscript and designed the figures. MN: provided extensive input regarding the focus and organization of the manuscript. PN: provided extensive editing and additional content to the manuscript. All authors contributed to the article and approved the submitted version.

\section{FUNDING}

This work was supported by NIH Grants P01AT003961, R01AI123947, R01AI129788, R01ES030144, and P20GM103641 to $\mathrm{PN}$ and $\mathrm{MN}$. 


\section{REFERENCES}

1. Birchenough GM, Johansson ME, Gustafsson JK, Bergstrom JH, Hansson GC. New developments in goblet cell mucus secretion and function. Mucosal Immunol. (2015) 8:712-9. doi: 10.1038/mi. 2015.32

2. Stevens CE, Leblond CP. Rate of renewal of the cells of the intestinal epithelium in the rat. Anat Rec. (1947) 97:373.

3. Creamer B, Shorter RG, Bamforth J. The turnover and shedding of epithelial cells. I The turnover in the gastro-intestinal tract Gut. (1961) 2:110-8.

4. Heath JP. Epithelial cell migration in the intestine. Cell Biol Int. (1996) 20:139-46.

5. Van Der Flier LG, Clevers H. Stem cells, self-renewal, and differentiation in the intestinal epithelium. Annu Rev Physiol. (2009) 71:241-60. doi: 10.1146/annurev.physiol.010908.163145

6. Medema JP, Vermeulen L. Microenvironmental regulation of stem cells in intestinal homeostasis and cancer. Nature. (2011) 474:318-26. doi: 10.1038/nature10212

7. Rothhammer V, Quintana FJ. The aryl hydrocarbon receptor: an environmental sensor integrating immune responses in health and disease. Nat Rev Immunol. (2019) 19:184-97. doi: 10.1038/s41577-0190125-8

8. Pernomian L, Duarte-Silva M, De Barros Cardoso CR. The Aryl Hydrocarbon Receptor (AHR) as a Potential Target for the Control of Intestinal Inflammation: insights from an Immune and Bacteria Sensor Receptor. Clin Rev Allergy Immunol. (2020) 59:382-90. doi: 10.1007/s12016-020-08789-3

9. Metidji A, Omenetti S, Crotta S, Li Y, Nye E, Ross E, et al. The environmental sensor AHR protects from inflammatory damage by maintaining intestinal stem cell homeostasis and barrier integrity. Immunity. (2018) 49:353-62. e355. doi: 10.1016/j.immuni.2018.07.010

10. Alvarado DM, Chen B, Iticovici M, Thaker AI, Dai N, Vandussen KL, et al. Epithelial indoleamine 2,3-dioxygenase 1 modulates aryl hydrocarbon receptor and notch signaling to increase differentiation of secretory cells and alter mucus-associated microbiota. Gastroenterology. (2019) 157:1093-108. e1011. doi: 10.1053/j.gastro.2019.07.013

11. Gronke K, Hernandez PP, Zimmermann J, Klose CSN, Kofoed-Branzk $\mathrm{M}$, Guendel F, et al. Interleukin-22 protects intestinal stem cells against genotoxic stress. Nature. (2019) 566:249-53. doi: 10.1038/s41586-0190899-7

12. Barker N, Van Es JH, Kuipers J, Kujala P, Van Den Born M, Cozijnsen M, et al. Identification of stem cells in small intestine and colon by marker gene Lgr5. Nature. (2007) 449:1003-7. doi: 10.1038/nature06196

13. Koo BK, Clevers H. Stem cells marked by the R-spondin receptor LGR5. Gastroenterology. (2014) 147:289-302. doi: 10.1053/j.gastro.2014. 05.007

14. Snippert HJ, Van Der Flier LG, Sato T, Van Es JH, Van Den Born M, Kroon-Veenboer C, et al. Intestinal crypt homeostasis results from neutral competition between symmetrically dividing Lgr5 stem cells. Cell. (2010) 143:134-44. doi: 10.1016/j.cell.2010.09.016

15. Ritsma L, Ellenbroek SIJ, Zomer A, Snippert HJ, De Sauvage FJ, Simons $\mathrm{BD}$, et al. Intestinal crypt homeostasis revealed at single-stem-cell level by in vivo live imaging. Nature. (2014) 507:362-5. doi: 10.1038/nature 12972

16. Tian H, Biehs B, Warming S, Leong KG, Rangell L, Klein OD, et al. A reserve stem cell population in small intestine renders Lgr5positive cells dispensable. Nature. (2011) 478:255-9. doi: 10.1038/nature 10408

17. Richmond CA, Rickner H, Shah MS, Ediger T, Deary L, Zhou F, et al. JAK/STAT-1 Signaling Is Required for Reserve Intestinal Stem Cell Activation during Intestinal Regeneration Following Acute Inflammation. Stem Cell Reports. (2018) 10:17-26. doi: 10.1016/j.stemcr.2017. 11.015

18. Valenta T, Degirmenci B, Moor AE, Herr P, Zimmerli D, Moor MB, et al. Wnt Ligands Secreted by Subepithelial Mesenchymal Cells Are Essential for the Survival of Intestinal Stem Cells and Gut Homeostasis. Cell Rep. (2016) 15:911-8. doi: 10.1016/j.celrep.2016.03.088
19. Stzepourginski I, Nigro G, Jacob JM, Dulauroy S, Sansonetti PJ, Eberl G, et al. CD34+ mesenchymal cells are a major component of the intestinal stem cells niche at homeostasis and after injury. Proc Natl Acad Sci U S A. (2017) 114:E506-E513. doi: 10.1073/pnas.1620059114

20. Shoshkes-Carmel M, Wang YJ, Wangensteen KJ, Toth B, Kondo A, Massasa EE, et al. Subepithelial telocytes are an important source of Wnts that supports intestinal crypts. Nature. (2018) 557:242-6. doi: 10.1038/s41586-018-0084-4

21. Spit M, Koo BK, Maurice MM. Tales from the crypt: intestinal niche signals in tissue renewal, plasticity and cancer. Open Biol. (2018) 8:180120. doi: 10.1098/rsob.180120

22. Bersten DC, Sullivan AE, Peet DJ, Whitelaw ML. bHLH-PAS proteins in cancer. Nat Rev Cancer. (2013) 13:827-41. doi: 10.1038/nrc3621

23. Denison MS, Nagy SR. Activation of the aryl hydrocarbon receptor by structurally diverse exogenous and endogenous chemicals. Annu Rev Pharmacol Toxicol. (2003) 43:309-34. doi: 10.1146/annurev.pharmtox.43.100901.135828

24. Pongratz I, Mason GG, Poellinger L. Dual roles of the $90-\mathrm{kDa}$ heat shock protein hsp90 in modulating functional activities of the dioxin receptor. Evidence that the dioxin receptor functionally belongs to a subclass of nuclear receptors which require hsp90 both for ligand binding activity and repression of intrinsic DNA binding activity. J Biol Chem. (1992) 267:1372834. doi: 10.1016/S0021-9258(18)42274-0

25. Kazlauskas A, Poellinger L, Pongratz I. The immunophilin-like protein XAP2 regulates ubiquitination and subcellular localization of the dioxin receptor. J Biol Chem. (2000) 275:41317-24. doi: 10.1074/jbc.M007765200

26. Meyer BK, Perdew GH. Characterization of the AhR-hsp90-XAP2 core complex and the role of the immunophilin-related protein XAP2 in AhR stabilization. Biochemistry. (1999) 38:8907-17. doi: 10.1021/bi98 $2223 \mathrm{w}$

27. Lapres JJ, Glover E, Dunham EE, Bunger MK, Bradfield CA. ARA9 modifies agonist signaling through an increase in cytosolic aryl hydrocarbon receptor. J Biol Chem. (2000) 275:6153-9. doi: 10.1074/jbc.275.9.6153

28. Ikuta T, Kobayashi Y, Kawajiri, K. Phosphorylation of nuclear localization signal inhibits the ligand-dependent nuclear import of aryl hydrocarbon receptor. Biochem Biophys Res Commun. (2004) 317:545-50. doi: 10.1016/j.bbrc.2004.03.076

29. Esser C, Rannug A, Stockinger B. The aryl hydrocarbon receptor in immunity. Trends Immunol. (2009) 30:447-54. doi: 10.1016/j.it.2009.06.005

30. Mcintosh BE, Hogenesch JB, Bradfield CA. Mammalian Per-Arnt-Sim proteins in environmental adaptation. Annu Rev Physiol. (2010) 72:625-45. doi: 10.1146/annurev-physiol-021909-135922

31. Schmidt JV, Bradfield CA. Ah receptor signaling pathways. Annu Rev Cell Dev Biol. (1996) 12:55-89. doi: 10.1146/annurev.cellbio.12.1.55

32. Beischlag TV, Luis Morales J, Hollingshead BD, Perdew GH. The aryl hydrocarbon receptor complex and the control of gene expression. Crit Rev Eukaryot Gene Expr. (2008) 18:207-50. doi: 10.1615/CritRevEukarGeneExpr.v18.i3.20

33. Pollenz RS. The aryl-hydrocarbon receptor, but not the aryl-hydrocarbon receptor nuclear translocator protein, is rapidly depleted in hepatic and nonhepatic culture cells exposed to 2,3,7,8-tetrachlorodibenzo-p-dioxin. Mol Pharmacol. (1996) 49:391-8.

34. Mimura J, Ema M, Sogawa K, Fujii-Kuriyama Y. Identification of a novel mechanism of regulation of Ah (dioxin) receptor function. Genes Dev. (1999) 13:20-5. doi: 10.1101/gad.13.1.20

35. Esser C, Rannug A. The aryl hydrocarbon receptor in barrier organ physiology, immunology, and toxicology. Pharmacol Rev. (2015) 67:259-79. doi: 10.1124/pr.114.009001

36. Aponte PM, Caicedo A. Stemness in Cancer: Stem Cells, Cancer Stem Cells, and Their Microenvironment. Stem Cells Int. (2017) 2017:5619472. doi: 10.1155/2017/5619472

37. Clevers H. Wnt/beta-catenin signaling in development and disease. Cell. (2006) 127:469-80. doi: 10.1016/j.cell.2006.10.018

38. Ireland H, Kemp R, Houghton C, Howard L, Clarke AR, Sansom OJ, et al. Inducible Cre-mediated control of gene expression in the murine gastrointestinal tract: effect of loss of beta-catenin. Gastroenterology. (2004) 126:1236-46. doi: 10.1053/j.gastro.2004.03.020 
39. Fevr T, Robine S, Louvard D, Huelsken J. Wnt/beta-catenin is essential for intestinal homeostasis and maintenance of intestinal stem cells. Mol Cell Biol. (2007) 27:7551-9. doi: 10.1128/MCB.01034-07

40. Behrens J, Lustig B. The Wnt connection to tumorigenesis. Int J Dev Biol. (2004) 48:477-87. doi: 10.1387/ijdb.041815jb

41. Novellasdemunt L, Antas P, Li VS. Targeting Wnt signaling in colorectal cancer. A Review in the Theme: Cell Signaling: Proteins, Pathways and Mechanisms Am J Physiol Cell Physiol. (2015) 309:C511-521. doi: 10.1152/ajpcell.00117.2015

42. Koo BK, Spit M, Jordens I, Low TY, Stange DE, Van De Wetering M, et al. Tumour suppressor RNF43 is a stem-cell E3 ligase that induces endocytosis of Wnt receptors. Nature. (2012) 488:665-9. doi: 10.1038/nature11308

43. Kasai S, Ishigaki T, Takumi R, Kamimura T, Kikuchi H. Beta-catenin signaling induces CYP1A1 expression by disrupting adherens junctions in Caco-2 human colon carcinoma cells. Biochim Biophys Acta. (2013) 1830:2509-16. doi: 10.1016/j.bbagen.2012.11.007

44. Shiizaki K, Kido K, Mizuta Y. Insight into the relationship between arylhydrocarbon receptor and beta-catenin in human colon cancer cells. PLoS ONE. (2019) 14:e0224613. doi: 10.1371/journal.pone.0224613

45. Sato T, Van Es JH, Snippert HJ, Stange DE, Vries RG, Van Den Born M, et al. Paneth cells constitute the niche for Lgr 5 stem cells in intestinal crypts. Nature. (2011) 469:415-8. doi: 10.1038/nature09637

46. Farin HF, Van Es JH, Clevers H. Redundant sources of Wnt regulate intestinal stem cells and promote formation of Paneth cells. Gastroenterology. (2012) 143:1518-29. e1517. doi: 10.1053/j.gastro.2012.08.031

47. Osaki LH, Gama P. MAPKs and signal transduction in the control of gastrointestinal epithelial cell proliferation and differentiation. Int J Mol Sci. (2013) 14:10143-61. doi: 10.3390/ijms140510143

48. Kabiri Z, Greicius G, Zaribafzadeh H, Hemmerich A, Counter CM, Virshup DM. Wnt signaling suppresses MAPK-driven proliferation of intestinal stem cells. J Clin Invest. (2018) 128:3806-12. doi: 10.1172/JCI99325

49. Agazie YM, Hayman MJ. Development of an efficient "substratetrapping" mutant of Src homology phosphotyrosine phosphatase 2 and identification of the epidermal growth factor receptor, Gab1, and three other proteins as target substrates. J Biol Chem. (2003) 278:13952-8. doi: 10.1074/jbc.M210670200

50. Coulombe G, Leblanc C, Cagnol S, Maloum F, Lemieux E, Perreault $\mathrm{N}$, et al. Epithelial tyrosine phosphatase SHP-2 protects against intestinal inflammation in mice. Mol Cell Biol. (2013) 33:2275-84. doi: 10.1128/MCB.00043-13

51. Gagne-Sansfacon J, Langlois A, Langlois MJ, Coulombe G, Tremblay S, Vaillancourt-Lavigueur V, et al. The tyrosine phosphatase Shp-2 confers resistance to colonic inflammation by driving goblet cell function and crypt regeneration. J Pathol. (2019) 247:135-46. doi: 10.1002/path.5177

52. Yin J, Yang K, Zhou C, Xu P, Xiao W, Yang H. Aryl hydrocarbon receptor activation alleviates dextran sodium sulfate-induced colitis through enhancing the differentiation of goblet cells. Biochem Biophys Res Commun. (2019) 514:180-6. doi: 10.1016/j.bbrc.2019.04.136

53. Fre S, Huyghe M, Mourikis P, Robine S, Louvard D, Artavanis-Tsakonas S. Notch signals control the fate of immature progenitor cells in the intestine. Nature. (2005) 435:964-8. doi: 10.1038/nature03589

54. Van Es JH, Van Gijn ME, Riccio O, Van Den Born M, Vooijs M, Begthel $\mathrm{H}$, et al. Notch/gamma-secretase inhibition turns proliferative cells in intestinal crypts and adenomas into goblet cells. Nature. (2005) 435:959-63. doi: $10.1038 /$ nature 03659

55. Bender DA. Effects of a dietary excess of leucine on the metabolism of tryptophan in the rat: a mechanism for the pellagragenic action of leucine. Br J Nutr. (1983) 50:25-32. doi: 10.1079/BJN19830068

56. Savitz J. The kynurenine pathway: a finger in every pie. Mol Psychiatry. (2020) 25:131-47. doi: 10.1038/s41380-019-0414-4

57. Rannug U, Rannug A, Sjoberg U, Li H, Westerholm R, Bergman J. Structure elucidation of two tryptophan-derived, high affinity Ah receptor ligands. Chem Biol. (1995) 2:841-5. doi: 10.1016/1074-5521(95)90090-X

58. Dinatale BC, Murray IA, Schroeder JC, Flaveny CA, Lahoti TS, Laurenzana EM, et al. Kynurenic acid is a potent endogenous aryl hydrocarbon receptor ligand that synergistically induces interleukin-6 in the presence of inflammatory signaling. Toxicol Sci. (2010) 115:89-97. doi: $10.1093 /$ toxsci/kfq024
59. Park JH, Lee JM, Lee EJ, Kim DJ, Hwang WB. Kynurenine promotes the goblet cell differentiation of HT-29 colon carcinoma cells by modulating Wnt, Notch and AhR signals. Oncol Rep. (2018) 39:1930-8. doi: 10.3892/or.2018.6266

60. Rannug A, Rannug U, Rosenkranz HS, Winqvist L, Westerholm R, Agurell $\mathrm{E}$, et al. Certain photooxidized derivatives of tryptophan bind with very high affinity to the Ah receptor and are likely to be endogenous signal substances. J Biol Chem. (1987) 262:15422-7. doi: 10.1016/S0021-9258(18)47743-5

61. Park JH, Choi AJ, Kim SJ, Cheong SW, Jeong SY. AhR activation by 6-formylindolo[3,2-b] carbazole and 2,3,7,8-tetrachlorodibenzo-p-dioxin inhibit the development of mouse intestinal epithelial cells. Environ Toxicol Pharmacol. (2016) 43:44-53. doi: 10.1016/j.etap.2016.02.007

62. Zinn C, Schofield G, Wall C. Evaluation of sports nutrition knowledge of New Zealand premier club rugby coaches. Int J Sport Nutr Exerc Metab. (2006) 16:214-25. doi: 10.1123/ijsnem.16.2.214

63. Nicholson JK, Holmes E, Kinross J, Burcelin R, Gibson G, Jia W, et al. Host-gut microbiota metabolic interactions. Science. (2012) 336:1262-7. doi: $10.1126 /$ science. 1223813

64. Koh A, De Vadder F, Kovatcheva-Datchary P, Backhed F. From Dietary Fiber to Host Physiology: Short-Chain Fatty Acids as Key Bacterial Metabolites. Cell. (2016) 165:1332-45. doi: 10.1016/j.cell.2016.05.041

65. Roager HM, Licht TR. Microbial tryptophan catabolites in health and disease. Nat Commun. (2018) 9:3294. doi: 10.1038/s41467-018-05470-4

66. Evenepoel P, Claus D, Geypens B, Hiele M, Geboes K, Rutgeerts $\mathrm{P}$, et al. Amount and fate of egg protein escaping assimilation in the small intestine of humans. Am J Physiol. (1999) 277:G935-943. doi: 10.1152/ajpgi.1999.277.5.G935

67. Gibson JA, Sladen GE, Dawson AM. Protein absorption and ammonia production: the effects of dietary protein and removal of the colon. Br J Nutr. (1976) 35:61-5. doi: 10.1079/BJN19760009

68. Vieira-Silva S, Falony G, Darzi Y, Lima-Mendez G, Garcia Yunta $\mathrm{R}$, Okuda S, et al. Species-function relationships shape ecological properties of the human gut microbiome. Nat Microbiol. (2016) 1:16088. doi: $10.1038 / \mathrm{nmicrobiol} .2016 .88$

69. Smith T. A Modification of the Method for Determining the Production of Indol by Bacteria. J Exp Med. (1897) 2:543-7. doi: 10.1084/jem.2.5.543

70. Deeley MC, Yanofsky C. Nucleotide sequence of the structural gene for tryptophanase of Escherichia coli K-12. J Bacteriol. (1981) 147:787-96. doi: 10.1128/JB.147.3.787-796.1981

71. Lee JH, Lee J. Indole as an intercellular signal in microbial communities. FEMS Microbiol Rev. (2010) 34:426-44. doi: 10.1111/j.1574-6976.2009.00204.x

72. Cervantes-Barragan L, Colonna M. AHR signaling in the development and function of intestinal immune cells and beyond. Semin Immunopathol. (2018) 40:371-7. doi: 10.1007/s00281-018-0694-9

73. Diefenbach A, Colonna M, Koyasu S. Development, differentiation, and diversity of innate lymphoid cells. Immunity. (2014) 41:354-65. doi: 10.1016/j.immuni.2014.09.005

74. Qiu J, Heller JJ, Guo X, Chen ZM, Fish K, Fu YX, et al. The aryl hydrocarbon receptor regulates gut immunity through modulation of innate lymphoid cells. Immunity. (2012) 36:92-104. doi: 10.1016/j.immuni.2011.11.011

75. Qiu J, Guo X, Chen ZM, He L, Sonnenberg GF, Artis D, et al. Group 3 innate lymphoid cells inhibit T-cell-mediated intestinal inflammation through aryl hydrocarbon receptor signaling and regulation of microflora. Immunity. (2013) 39:386-99. doi: 10.1016/j.immuni.2013.08.002

76. Lindemans CA, Calafiore M, Mertelsmann AM, O'connor MH, Dudakov JA, Jenq RR, et al. Interleukin-22 promotes intestinal-stem-cell-mediated epithelial regeneration. Nature. (2015) 528:560-4. doi: 10.1038/nature16460

77. Alam MS, Maekawa Y, Kitamura A, Tanigaki K, Yoshimoto T, Kishihara K, et al. Notch signaling drives IL-22 secretion in CD4+ T cells by stimulating the aryl hydrocarbon receptor. Proc Natl Acad Sci U S A. (2010) 107:5943-8. doi: 10.1073/pnas.0911755107

78. Lee JS, Cella M, Mcdonald KG, Garlanda C, Kennedy GD, Nukaya M, et al. AHR drives the development of gut ILC22 cells and postnatal lymphoid tissues via pathways dependent on and independent of Notch. Nat Immunol. (2011) 13:144-51. doi: 10.1038/ni.2187

79. Weidenbusch M, Rodler S, Song S, Romoli S, Marschner JA, Kraft F, et al. Gene expression profiling of the Notch-AhR-IL22 axis at homeostasis 
and in response to tissue injury. Biosci Rep. 37. doi: 10.1042/BSR201 70099

80. Zelante T, Iannitti RG, Cunha C, De Luca A, Giovannini G, Pieraccini $\mathrm{G}$, et al. Tryptophan catabolites from microbiota engage aryl hydrocarbon receptor and balance mucosal reactivity via interleukin-22. Immunity. (2013) 39:372-85. doi: 10.1016/j.immuni.2013.08.003

81. Hou Q, Ye L, Liu H, Huang L, Yang Q, Turner JR, et al. Lactobacillus accelerates ISCs regeneration to protect the integrity of intestinal mucosa through activation of STAT3 signaling pathway induced by LPLs secretion of IL-22. Cell Death Differ. (2018) 25:1657-70. doi: 10.1038/s41418-018-0070-2

82. Engelhardt KR, Grimbacher B. IL-10 in humans: lessons from the gut, IL-10/IL-10 receptor deficiencies, and IL-10 polymorphisms. Curr Top Microbiol Immunol. (2014) 380:1-18. doi: 10.1007/978-3-662-43492-5_1

83. Hasnain SZ, Tauro S, Das I, Tong H, Chen AC, Jeffery PL, et al. IL-10 promotes production of intestinal mucus by suppressing protein misfolding and endoplasmic reticulum stress in goblet cells. Gastroenterology. (2013) 144:357-68. e359. doi: 10.1053/j.gastro.2012.10.043

84. Berkowitz L, Pardo-Roa C, Ramirez G, Vallejos OP, Sebastian VP, Riedel CA, et al. The absence of interleukin 10 affects the morphology, differentiation, granule content and the production of cryptidin-4 in Paneth cells in mice. PLoS ONE. (2019) 14:e221618. doi: 10.1371/journal.pone.0221618

85. Alexeev EE, Lanis JM, Kao DJ, Campbell EL, Kelly CJ, Battista KD, et al. Microbiota-Derived Indole Metabolites Promote Human and Murine Intestinal Homeostasis through Regulation of Interleukin-10 Receptor. Am J Pathol. (2018) 188:1183-94. doi: 10.1016/j.ajpath.2018.01.011

86. Macfarlane S, Macfarlane GT. Regulation of short-chain fatty acid production. Proc Nutr Soc. (2003) 62:67-72. doi: 10.1079/PNS2002207

87. Savage DC. Gastrointestinal microflora in mammalian nutrition. Annu Rev Nutr. (1986) 6:155-78. doi: 10.1146/annurev.nu.06.070186.001103

88. Kuwahara A. Contributions of colonic short-chain Fatty Acid receptors in energy homeostasis. Front Endocrinol (Lausanne). (2014) 5:144. doi: 10.3389/fendo.2014.00144

89. Donohoe DR, Garge N, Zhang X, Sun W, O'connell TM, Bunger $\mathrm{MK}$, et al. The microbiome and butyrate regulate energy metabolism and autophagy in the mammalian colon. Cell Metab. (2011) 13:517-26. doi: 10.1016/j.cmet.2011.02.018

90. Segain JP, Raingeard De La Bletiere D, Bourreille A, Leray V, Gervois $\mathrm{N}$, Rosales $\mathrm{C}$, et al. Butyrate inhibits inflammatory responses through NFkappaB inhibition: implications for Crohn's disease. Gut. (2000) 47:397403. doi: 10.1136/gut.47.3.397

91. Fung KY, Cosgrove L, Lockett T, Head R, Topping DL. A review of the potential mechanisms for the lowering of colorectal oncogenesis by butyrate. Br J Nutr. (2012) 108:820-31. doi: 10.1017/S0007114512001948

92. Arpaia N, Campbell C, Fan X, Dikiy S, Van Der Veeken J, Deroos P, et al. Metabolites produced by commensal bacteria promote peripheral regulatory T-cell generation. Nature. (2013) 504:451-5. doi: 10.1038/nature 12726

93. Bachmann M, Meissner C, Pfeilschifter J, Muhl H. Cooperation between the bacterial-derived short-chain fatty acid butyrate and interleukin-22 detected in human Caco2 colon epithelial/carcinoma cells. Biofactors. (2017) 43:28392. doi: 10.1002/biof.1341

94. Jin UH, Cheng Y, Park H, Davidson LA, Callaway ES, Chapkin RS, et al. Short Chain Fatty Acids Enhance Aryl Hydrocarbon (Ah) Responsiveness in Mouse Colonocytes and Caco-2 Human Colon Cancer Cells. Sci Rep. (2017) 7:10163. doi: 10.1038/s41598-017-10824-x

95. Marinelli L, Martin-Gallausiaux C, Bourhis JM, Beguet-Crespel F, Blottiere $\mathrm{HM}$, Lapaque N. Identification of the novel role of butyrate as AhR ligand in human intestinal epithelial cells. Sci Rep. (2019) 9:643. doi: 10.1038/s41598-018-37019-2

96. Xing PY, Pettersson S, Kundu P. Microbial Metabolites and Intestinal Stem Cells Tune Intestinal Homeostasis. Proteomics. (2020) 20:e1800419. doi: 10.1002/pmic.201800419

97. Blottiere HM, Buecher B, Galmiche JP, Cherbut C. Molecular analysis of the effect of short-chain fatty acids on intestinal cell proliferation. Proc Nutr Soc. (2003) 62:101-6. doi: 10.1079/PNS2002215

98. Mortensen FV, Nielsen H, Mulvany MJ, Hessov I. Short chain fatty acids dilate isolated human colonic resistance arteries. Gut. (1990) 31:1391-4. doi: 10.1136/gut.31.12.1391
99. Kaiko GE, Ryu SH, Koues OI, Collins PL, Solnica-Krezel L, Pearce EJ, et al. The Colonic Crypt Protects Stem Cells from Microbiota-Derived Metabolites. Cell. (2016) 165:1708-20. doi: 10.1016/j.cell.2016.05.018

100. Vezza T, Rodriguez-Nogales A, Algieri F, Utrilla MP, Rodriguez-Cabezas ME, Galvez J. Flavonoids in inflammatory bowel disease: a review. Nutrients. (2016) 8:211. doi: 10.3390/nu8040211

101. Busbee PB, Rouse M, Nagarkatti M, Nagarkatti PS. Use of natural AhR ligands as potential therapeutic modalities against inflammatory disorders. Nutr Rev. (2013) 71:353-69. doi: 10.1111/nure.12024

102. Lamson DW, Brignall MS. Antioxidants and cancer, part 3: quercetin. Altern Med Rev. (2000) 5:196-208.

103. Jang M, Cai L, Udeani GO, Slowing KV, Thomas CF, Beecher CW, et al. Cancer chemopreventive activity of resveratrol, a natural product derived from grapes. Science. (1997) 275:218-20. doi: 10.1126/science.275.5297.218

104. Mohammadi-Bardbori A, Bengtsson J, Rannug U, Rannug A, Wincent E. Quercetin, resveratrol, and curcumin are indirect activators of the aryl hydrocarbon receptor (AHR). Chem Res Toxicol. (2012) 25:1878-84. doi: $10.1021 / \mathrm{tx} 300169 \mathrm{e}$

105. Janssen KP, Alberici P, Fsihi H, Gaspar C, Breukel C, Franken P, et al. APC and oncogenic KRAS are synergistic in enhancing Wnt signaling in intestinal tumor formation and progression. Gastroenterology. (2006) 131:1096-109. doi: 10.1053/j.gastro.2006.08.011

106. Brandt R, Sell T, Luthen M, Uhlitz F, Klinger B, Riemer P, et al. Cell type-dependent differential activation of ERK by oncogenic KRAS in colon cancer and intestinal epithelium. Nat Commun. (2019) 10:2919. doi: 10.1038/s41467-019-10954-y

107. Gupta SC, Kannappan R, Reuter S, Kim JH, Aggarwal BB. Chemosensitization of tumors by resveratrol. Ann N Y Acad Sci. (2011) 1215:150-60. doi: 10.1111/j.1749-6632.2010.05852.x

108. Saud SM, Li W, Morris NL, Matter MS, Colburn NH, Kim YS, et al. Resveratrol prevents tumorigenesis in mouse model of Kras activated sporadic colorectal cancer by suppressing oncogenic Kras expression. Carcinogenesis. (2014) 35:2778-86. doi: 10.1093/carcin/bgu209

109. Yu S, Lu Z, Liu C, Meng Y, Ma Y, Zhao W, et al. miRNA-96 suppresses KRAS and functions as a tumor suppressor gene in pancreatic cancer. Cancer Res. (2010) 70:6015-25. doi: 10.1158/0008-5472.CAN-09-4531

110. Tanaka M, Suzuki HI, Shibahara J, Kunita A, Isagawa T, Yoshimi A, et al. EVI1 oncogene promotes KRAS pathway through suppression of microRNA-96 in pancreatic carcinogenesis. Oncogene. (2014) 33:2454-63. doi: 10.1038/onc.2013.204

111. Damiano S, Sasso A, De Felice B, Di Gregorio I, La Rosa G, Lupoli GA, et al. Quercetin Increases MUC2 and MUC5AC Gene Expression and Secretion in Intestinal Goblet Cell-Like LS174T via PLC/PKCalpha/ERK1-2 Pathway. Front Physiol. (2018) 9:357. doi: 10.3389/fphys.2018.00357

112. Singh RK, Kumar S, Gautam PK, Tomar MS, Verma PK, Singh SP, et al. Protein kinase $\mathrm{C}$-alpha and the regulation of diverse cell responses. Biomol Concepts. (2017) 8:143-53. doi: 10.1515/bmc-2017-0005

113. Clark JA, Black AR, Leontieva OV, Frey MR, Pysz MA, Kunneva L, et al. Involvement of the ERK signaling cascade in protein kinase C-mediated cell cycle arrest in intestinal epithelial cells. J Biol Chem. (2004) 279:9233-47. doi: 10.1074/jbc.M312268200

114. Rogers S, De Souza AR, Zago M, Iu M, Guerrina N, Gomez A, et al. Aryl hydrocarbon receptor (AhR)-dependent regulation of pulmonary miRNA by chronic cigarette smoke exposure. Sci Rep. (2017) 7:40539. doi: 10.1038/srep40539

115. Bjeldanes LF, Kim JY, Grose KR, Bartholomew JC, Bradfield CA. Aromatic hydrocarbon responsiveness-receptor agonists generated from indole-3-carbinol in vitro and in vivo: comparisons with 2,3,7,8tetrachlorodibenzo-p-dioxin. Proc Natl Acad Sci U S A. (1991) 88:9543-7. doi: 10.1073/pnas.88.21.9543

116. Busbee PB, Menzel L, Alrafas HR, Dopkins N, Becker W, Miranda $\mathrm{K}$, et al. Indole-3-carbinol prevents colitis and associated microbial dysbiosis in an IL-22-dependent manner. JCI Insight. (2020) 5:e127551. doi: 10.1172/jci.insight.127551

117. Park JH, Lee JM, Lee EJ, Hwang WB, Kim DJ. Indole-3-carbinol promotes goblet-cell differentiation regulating Wnt and notch signaling pathways AhR-dependently. Mol Cells. (2018) 41:290-300. doi: 10.14348/molcells.2018.2167 
118. Pellizzon M. Choice of laboratory animal diet influences intestinal health. Lab Anim (NY). (2016) 45:238-9. doi: 10.1038/lab an. 1014

Conflict of Interest: The authors declare that the research was conducted in the absence of any commercial or financial relationships that could be construed as a potential conflict of interest.
Copyright $\odot 2021$ Wisniewski, Nagarkatti and Nagarkatti. This is an open-access article distributed under the terms of the Creative Commons Attribution License (CC $B Y)$. The use, distribution or reproduction in other forums is permitted, provided the original author(s) and the copyright owner(s) are credited and that the original publication in this journal is cited, in accordance with accepted academic practice. No use, distribution or reproduction is permitted which does not comply with these terms. 